\title{
INCIDÊNCIA DO IMPOSTO DE RENDA NAS SUCESSÕES CAUSA MORTIS DECORRENTE DE GANHO DE CAPITAL
}

\author{
Jair Kulitch ${ }^{1}$
}

\begin{abstract}
RESUMO: O presente trabalho busca esclarecer sobre a tributação sobre a renda, em especial à oriunda de ganho de capital na sucessão causa mortis. Um dos fatores preponderantes é entender o Estado como detentor da competência tributária, bem como espécies, finalidades e importâncias dos tributos. Buscouse através de análise da legislação sobre assunto, confrontar o posicionamento da doutrina e jurisprudência para descobrir o verdadeiro sentido dos termos empregados. Necessário se fez analisar importantes elementos para o Direito Tributário, como hipótese de incidência tributária, fato gerador, sujeito passivo, responsável tributário, além de conceitos como renda.
\end{abstract}

PALAVRAS-CHAVES: Imposto De Renda; Sucessão Causa Mortis; Ganho De Capital.

\section{INCIDENCE OF INCOME TAXES IN SUCCESSIONS CAUSES MORTIS FROM CAPITAL GAIN}

\begin{abstract}
The present article seeks to clarify taxation on income, especially that derived from capital gain in succession in case of death. One of the preponderant factors is to understand the State as holder of the tax jurisdiction, as well as species, purposes and importance of the taxes. It was sought through analysis of legislation on the subject, to confront the position of doctrine and jurisprudence to discover the true meaning of the terms employed. It was necessary to analyze important elements for Tax Law, as hypothesis of tax incidence, taxable event, taxpayer, as well as concepts such as income.
\end{abstract}

KEY WORDS: Income Tax; Succession "Cause Mortis"; Capital Gains

\section{INTRODUÇÃO}

Muito se discute o complexo e delicado sistema tributário nacional, em especial a alta carga sobre o produto interno bruto e os efeitos que dela decorre para o crescimento do país. Tanto pessoas jurídicas quanto físicas sofrem com a quantidade de normas tributárias que, além de complexas, modificam quase diariamente.

\footnotetext{
${ }^{1}$ Aluno do Curso de Mestrado em Direito Empresarial e Cidadania pela UNICURITIBA. Pós-Graduado em Direito Processual Civil e Direito Civil com Ênfase em Prática Civil do Centro de Ensino Superior dos Campos Gerais; Pós-Graduado em Direito do Trabalho e Processo do Trabalho pela Universidade Estadual de Ponta Grossa UEPF; Pós-Graduado em Direito Tributário e Processo Tributário pela Universidade Anhanguera-Uniderp. Endereço postal: Rua Dr. Munhoz da Rocha, 384, centro, CEP 84500-000, em Irati - PR. Endereço eletrônico: jair.kulitch@uol.com.br
} 


\section{INCIDÊNCIA DO IMPOSTO DE RENDA NAS SUCESSÕES CAUSA MORTIS DECORRENTE DE GANHO DE CAPITAL}

Um dos grandes questionamentos de todos os contribuintes é a incidência de tributos sobre a renda, haja vista que retira do contribuinte grande parte de seu poder aquisitivo, sem aparente contraprestação do Estado.

O problema da destinação dos recursos obtidos através dos tributos é uma questão política, devendo ser questionada juridicamente por meio de outros recursos, como uma melhor fiscalização e cobrança junto aos órgãos competentes. A compulsoriedade dos tributos não deve ser discutida sob esse aspecto. Ela é necessária ao Estado.

Todos os questionamentos devem sempre ser oferecidos aos órgãos competentes e, em última análise, ao Poder Judiciário, com base em dados técnicos, discutindo-se conceitos e alcance das normas jurídicas.

O Estado tem possibilidade de instituir tributos, mas deve fazer respeitando a Constituição Federal e seus princípios, e ainda, os elementos constitutivos de cada espécie de tributo, em especial ao fato gerador, nascedouro da obrigação tributária.

Os conteúdos dos termos jurídicos têm seu alcance delimitado, não sendo permitida utilização de um mesmo instituto para designar outros, independentemente do motivo que, algumas vezes, pode até parecer legítimos num primeiro plano.

As regras para criação ou majoração de tributo devem ser obedecidas para não ameaçar a segurança jurídica nem colocar em xeque a existência do Estado de Direito, muito menos o Estado Democrático de Direito.

O Estado deve utilizar a competência constitucional para instituir tributos quando for necessário, respeitando sua finalidade essencial, que é custear as despesas estatais. O mesmo deve acontecer com toda e qualquer forma de majoração. Somente serão legítimas se houver necessidade de atender demandas sociais.

Utilizar desses institutos para criação de nova obrigação tributária somente para aumentar receita não é permitido, sob pena de violar normas e princípios constitucionais, dentre eles da vedação ao confisco, além de ofuscar a verdadeira finalidade dos tributos.

Não é juridicamente permitido alargar interpretação dada aos fundamentos que norteiam as hipóteses de incidência tributária, construídos ao longo de muitos anos, às duras penas na árdua relação fisco e contribuinte, especialmente quando em desfavor a este.

A obrigação tributária também não pode ser atribuída a qualquer pessoa, somente para facilitar a fiscalização e cobrança dos tributos. O Estado deve buscar os meios legais e legítimos para tanto, sob pena de violar conceitos jurídicos deveras importantes, em especial da responsabilidade tributária e da manifestação de riqueza. 
Somente com a elaboração de normas coerentes juridicamente e seu devido cumprimento, principalmente pelo ente tributante, é que será possível a construção de um Estado de Direito. O aprimoramento das normas deve ocorrer diuturnamente, através do Poder Legislativo, contemporanizando as já existentes, permitindo com que o Poder Judiciário possa fazer justiça ao caso concreto, e não o inverso, para o bem da dialética do direito.

No caso específico do imposto sobre a renda, deve-se levar em consideração o conceito que mais se aproxime de renda, não podendo ser tributado qualquer rendimento que incorpore ao patrimônio de determinado indivíduo, sem que dele tenha participado em seus elementos constitutivos.

Quando o auferimento de renda decorrer de situação esporádica, a tributação deve sopesar o fato gerador, além da participação do contribuinte na ocorrência deste, para que o tributo possa incidir de forma justa.

Não se pode permitir que determinado ganho sofra tributação em razão de alguns fatos irrelevantes, quando em sua essência, a incidência já é pacificamente dispensada.

Com a edição da Lei ${ }^{0}$ 9532/1997, inseriu-se no sistema tributário a possibilidade de tributação nas sucessões causa mortis, quando ocorrer diferença, a maior, entre o valor de aquisição do bem pelo finado e o valor transmitido no inventário.

Inovou-se a forma de tributação no chamado de ganho de capital, não se limitando a transmissão da propriedade por ato inter vivos. Todavia, esta possibilidade de tributação deve ser analisada detidamente, tanto nos termos jurídicos que norteiam qualquer espécie de obrigação tributária e ainda, quanto na específica relativa ao ganho de capital puro.

Diante deste contexto, mostra-se relevante analisar detalhadamente o arcabouço estatal, sua instituição e finalidade, bem como seus direitos e obrigações, em especial no direito tributário.

Também, há necessidade de esmiuçar conceitos técnicos de termos jurídicos, atividade deveras importante para o conhecimento da finalidade de determinadas normas e ainda, que inversão de valores pode acarretar grande enfraquecimento do cidadão frente ao Estado.

O objetivo do presente artigo é identificar a possibilidade jurídica da instituição do imposto decorrente do ganho de capital nas sucessões causa-mortis e sua eventual infringência aos elementos do direito tributário, além dos princípios constitucionais que limitam o Estado na imposição de tributos.

\section{TRIBUTO}




\section{INCIDÊNCIA DO IMPOSTO DE RENDA NAS SUCESSÕES CAUSA MORTIS DECORRENTE DE GANHO DE CAPITAL}

O conceito de tributo não se encontra definido no manto constitucional, devendo tal tarefa ser externada por Lei Complementar, nos termos do artigo 146, inciso III da Constituição Federal. Esta missão vem sendo exercida pelo Código Tributário Nacional que, embora não tenha características formais de Lei Complementar, assim o foi recepcionado.

Em termos de referência legislativa, o tributo vem conceituado de longa data através do Código Tributário Nacional que, em seu artigo $3^{\circ}$, o define da seguinte forma:

Art. $3^{\circ}$ Tributo é toda prestação pecuniária compulsória, em moeda ou cujo valor nela se possa exprimir, que não constitua sanção de ato ilícito, instituída em lei e cobrada mediante atividade administrativa plenamente vinculada.

Saber distinguir tributo de outras receitas é relevante, posto que pode ou não atrair princípios, imunidades e limitações previstos no texto constitucional. Dentre os elementos constantes no artigo supra referido, alguns merecem destaque para que se possa entender melhor a extensão dos tributos.

A primeira delas refere-se a prestação, que assim é explicado por Luis Eduardo Schoueri (2012, pág. 132): “Ao empregar o termo "prestação”, o legislador complementar já informa que se pode falar em “obrigação tributária”, já que a prestação é o objeto do cumprimento de uma obrigação.”

Os termos “pecuniária” e “em moeda, ou cujo valor nela se possa exprimir” traz a ideia de transferência de valores monetários. Considerando que o pagamento tem por finalidade a extinção do crédito tributário, nos termos do artigo 156 do CTN, é possível perceber que há outras formas de extinção, como a dação em pagamento, conforme inciso XI do referido artigo.

Todavia, essa é uma forma atípica de extinguir o crédito tributário. Nos dias atuais, é muito comum a recusa pelos agentes bancários o recebimento em cheque para pagamento de algum tipo de tributo. Somente em dinheiro, o que torna mais evidente as expressões previstas pelo artigo $3^{\circ}$ do CTN.

A referência à "prestação compulsória” decorre da soberania estatal. É instituído o tributo em prol do bem comum, da sociedade em geral, por vontade desta. Não é permitido ao cidadão optar pelo pagamento ou não.

Faz-se referência ao termo "lei”, em prestígio ao princípio da legalidade, embora o disposto no CTN anteveio a promulgação da CF/1988. É de salutar importância que aqui se faz referência à Lei Complementar, nos termos do artigo 146 da CF/1988. 
O tributo é atividade estatal plenamente vinculada, conforme prescreve o CTN. Assim o é em razão do princípio da isonomia, não podendo o ente tributante cobrar tributos de determinadas pessoas, sob o fundamento da discricionariedade.

Ao efetuar a cobrança de determinado tributo, o governante não está exercendo ato próprio e sim do Estado, que age por determinação da sociedade.

\section{DO IMPOSTO DE RENDA}

De competência da União Federal, nos termos do artigo 153, inciso III da CF/1988, atribuindo-se legitimidade para instituir impostos sobre renda e proventos de qualquer natureza, tem suas bases insculpidas no artigo 43 do CTN, in verbis:

Art. 43. O imposto, de competência da União, sobre a renda e proventos de qualquer natureza tem como fato gerador a aquisição da disponibilidade econômica ou jurídica:

I - de renda, assim entendido o produto do capital, do trabalho ou da combinação de ambos;

II - de proventos de qualquer natureza, assim entendidos os acréscimos patrimoniais não compreendidos no inciso anterior.

$\S 1^{\circ} \mathrm{A}$ incidência do imposto independe da denominação da receita ou do rendimento, da localização, condição jurídica ou nacionalidade da fonte, da origem e da forma de percepção. (Parágrafo acrescentado conforme determinado na Lei Complementar $\mathrm{n}^{\circ}$ 104, de 10.1.2001, DOU 11.1.2001)

$\S 2^{\circ} \mathrm{Na}$ hipótese de receita ou de rendimento oriundos do exterior, a lei estabelecerá as condições e o momento em que se dará sua disponibilidade, para fins de incidência do imposto referido neste artigo. (Parágrafo acrescentado conforme determinado na Lei Complementar $\mathrm{n}^{\circ} 104$, de 10.1.2001, DOU 11.1.2001)

Em razão da Constituição não conceituar nem esmiuçar sobre tributos, o Código

Tributário assim o fez, traçando importantes elementos. Primeiro que o imposto incidirá sobre a renda e proventos de qualquer natureza, delimitando seu objeto.

Em segundo lugar, traz como fato gerador ou hipótese de incidência a aquisição ou disponibilidade econômica ou jurídica. Qual ocorrer primeiro irá configurar fato gerador.

No inciso I, o legislador ordinário trouxe conceito para renda dizendo tratar-se do produto do capital, do trabalho ou da combinação de ambos. No inciso II, apresentou como hipótese de incidência também os proventos de qualquer natureza, eliminando qualquer lacuna 


\section{INCIDÊNCIA DO IMPOSTO DE RENDA NAS SUCESSÕES CAUSA MORTIS DECORRENTE DE GANHO DE CAPITAL}

ao completar dizendo que referidos proventos são entendidos os acréscimos patrimoniais não compreendidos no inciso anterior.

No parágrafo primeiro informou que não tem o menor interesse, para fins de tributação, a denominação da renda ou rendimento. Também não importa quem seja a fonte dos recursos, muito menos a forma com que são percebidos.

Se a receita ou rendimentos provierem do exterior, a lei específica irá estabelecer detalhes de ordem tributária.

A base de cálculo, por óbvio, é o montante da renda ou dos proventos, podendo ser real, arbitrado ou presumido.

Por fim, informou o legislador ordinário que o contribuinte é aquele que for titular da disponibilidade da renda ou dos proventos, podendo ser considerado contribuinte também aquele que for detentor dos bens produtores de renda.

Atribuiu também à fonte pagadora a possibilidade de ser responsável pelo recolhimento, antes de disponibilizar a renda ou proventos ao seu titular, na condição de responsável, nos termos do artigo 121, parágrafo único, inciso II do CTN.

Para Hugo de Brito Machado (2012, pág. 318), o imposto de renda “... tem como âmbito constitucional de incidência a aquisição de disponibilidade econômica ou jurídica de quaisquer acréscimos patrimoniais”.

Referido doutrinador refuta a ideia de permitir ao legislador ordinário a possibilidade de conceituar renda (Hugo de Brito Machado 2012, pág. 319):

Realmente, admitir que o legislador ordinário é livre para definir o que é renda, para fins tributários, implica admitir que o legislador ordinário modifique a Constituição, dando às suas regras o sentido e o alcance que lhe parecerem convenientes - o que constitui evidente absurdo jurídico.

Todavia, a CF/1988 faz menção a importante previsão quanto aos critérios, informando no parágrafo segundo do artigo 153, que o imposto em questão será informado pelos critérios da generalidade, da universalidade e da progressividade, na forma da lei.

Quanto ao primeiro, guarda relação com o universo de pessoas que realizam o fato imponível. De modo geral, todos sofrem tributação. O critério da progressividade é caracterizado pela aplicação da alíquota em relação a base de cálculo. Quanto maior esta, maior será aquela, em prestígio ao princípio da capacidade contributiva.

Problema maior se encontra no critério da universalidade que, segundo Roque Antonio Carraza (2009, pág. 71) “... impõe que todos os rendimentos do contribuinte sejam 
considerados globalmente, dentro do mesmo período de apuração, que há de ter, portanto, idêntico dies a quo e dies ad quem.

Esse princípio é levado a cabo pelo legislador ordinário, ao considerar como tributável uma vasta gama de receita. É o que se constata da análise também do Decreto n ${ }^{0} 3000$, de 26 de março de 1999, publicado no DOU de 29/03/1999, republicado em 17/06/1999, que Regulamenta a tributação, fiscalização, arrecadação e administração do Imposto sobre a Renda e Proventos de Qualquer Natureza, em especial ao Capítulo III, que trata dos rendimentos tributáveis no artigo 43 e seguintes.

É claro que os verbos do tipo tributário é aquisição ou disponibilidade econômica, sendo essas as ações a serem praticadas pelo sujeito passivo para caracterizar o fato gerador. Assim doutrinam Leandro Paulsen e José Eduardo Soares de Melo (2012, pág. 61), com auxílio de dicionários da língua portuguesa:

“Aquisição” é o ato de adquirir, ou seja, de obter, conseguir, passar a ter. "Disponibilidade” é a qualidade ou estado do que é disponível, do que se pode usar livremente, é a "qualidade dos valores e títulos integrantes do ativo dum comerciante, que podem dispor imediatamente ou converter em numerário.”

A doutrina tem se debruçado sobre o tema, em especial em definir o que seria o núcleo do tipo tributário, que constituem a hipótese de incidência: auferir renda e proventos de qualquer natureza ou acréscimo patrimonial decorrente desse fato. Para Eduardo Sabbag (2012, pág. 1133) seria a segunda opção:

O imposto tem como hipótese de sua incidência o acréscimo patrimonial, em razão da aquisição da disponibilidade econômica ou jurídica da renda decorrente do capital, do trabalho ou da combinação de ambos, além de proventos de qualquer natureza.

Todavia, o termo central “acréscimo patrimonial” deve ser entendido sob a perspectiva de aquisição ou da disponibilidade econômica da renda. Atribuir conceito de "lucro" é totalmente equivocado.

Gisele Lemke (1998, pág. 61-62), ao elaborar uma obra doutrinária específica sobre o tema, assim se posiciona quando a regra matriz de incidência do Imposto de Renda:

Os doutrinadores em geral entendem que o Direito brasileiro adotou a teoria do acréscimo patrimonial para a conceituação de renda. Isso decorre do fato de o Código falar em produto do capital, do trabalho, da combinação de ambos e nos acréscimos patrimoniais não compreendidos no inciso I. Vale dizer, 


\section{INCIDÊNCIA DO IMPOSTO DE RENDA NAS SUCESSÕES CAUSA MORTIS DECORRENTE DE GANHO DE CAPITAL}

reúnem-se os conceitos de renda e proventos num só, de renda em sentido amplo, por não se considerar muito técnica a alusão a proventos.

Parece existir, contudo, um equívoco na asserção pura e simples de que a teoria adotada pelo Código é a do acréscimo patrimonial. É que, em seu sentido estrito, o acréscimo patrimonial não envolve os rendimentos consumidos.

Diante disso, conclui-se que o acréscimo patrimonial tem a ver com disponibilidade econômica e jurídica e não com aumento efetivo de patrimônio, considerando o conjunto de bens e direitos.

A legislação pátria permite dedução de alguns elementos para efeitos de tributação, como prescreve o artigo 73 do Decreto 3000/1999, e não todas as despesas com o custeio da renda ou provento.

Passo seguinte é a concepção jurídica para fins de tributação de renda e proventos de qualquer natureza.

Para Eduardo Sabbag (2012, pág. 1134), renda pode ser decorrente de capital, oriunda de aluguel, recebimentos decorrentes de aplicações financeiras, lucros, etc.; do trabalho, proveniente de salário, honorários, pró-labore; da combinação do capital e do trabalho, como pró-labore, lucro, etc. Pode ainda ser caracterizada como proventos de qualquer natureza, as aposentadorias, pensões, ganhos em loterias, doações, acréscimos patrimoniais não justificáveis, etc.

Entretanto, a jurista Gisele Lemke (1998, pág. 63) faz uma análise mais minuciosa sobre o vocábulo “renda”, empregado pelo CTN:

Ao definir a renda (em sentido estrito) como o produto do capital, do trabalho ou da combinação de ambos, o Código Tributário adotou a teoria da rendaproduto ou a teoria das fontes. Isso não significa que tenha sido adotada essa teoria com todos os elementos colocados pelos partidários para a conceituação de renda. Até porque eles mesmos divergem entre si. Quando se afirma que o Código adotou a teoria das fontes, o que se pretende é dizer que ele excluiu a teoria da renda-acréscimo patrimonial para a definição de renda (em sentido estrito), exigindo que esta decorra de uma fonte produtiva (capital, trabalho ou a combinação de ambos). Ficam excluídos dessa definição, portanto, os acréscimos patrimoniais gratuitos, como as mais-valias, já que eles não se originam do emprego do capital do contribuinte (nem, evidentemente, do seu trabalho nem da combinação de ambos). Originam-se de causas fortuitas. Assim, as mais-valias, por exemplo, não se classificam como a renda em sentido estrito, porque não são produto do capital. Há um simples aumento de valor do patrimônio, porém nada foi produzido por ele.

Quanto ao conceito de provento, Mary Elbe Queiroz (2004, p.69) assim transcreve: 
b) provento é forma específica de rendimento tributável, tecnicamente compreendida como o que é 'fruto não da realização imediata e simultânea de um patrimônio, mas sim, do acréscimo patrimonial resultante de uma atividade que já cessou, mas que ainda produz rendimentos', como os benefícios de origem previdenciária, pensões e aposentadoria. Já proventos em acepção ampla, como acréscimos patrimoniais não resultantes do capital ou do trabalho, são todos aqueles de 'origem ilícitas e bem aqueles cuja origem não seja identificável ou comprovável”;

Também a escritora Gisele Lemke (1998, p. 65-66) faz referência ao termo proventos:

Quanto ao significado da expressão "proventos”, é de se concordar com Mario Caldeira de Andrade e com Rubens Gomes de Souza. Proventos, segundo estabelece o Código Tributário Nacional, são todos os acréscimos patrimoniais não incluídos na noção de renda da teoria das fontes, independentemente de sua origem, sendo que os mais frequentes são as maisvalias.

Já o Professor Vladimir Passos de Freitas (2007, pág. 179), fazendo referências a Rubens Gomes de Sousa, Allix e Jèze, afasta da possibilidade de se considerar como renda o ingresso de disponibilidade financeira que decorrer de fatos esporádicos:

Com isso, ficariam afastadas do conceito de renda "certas receitas decorrentes de circunstâncias puramente fortuitas, para as quais o titular em nada concorreu: numa palavra, o que os norte americanos chamam um windfall”, como a herança e as doações.

Porém, todos esses conceitos de renda e proventos dão a ideia de certa periodicidade no aferimento ou simples disponibilidade. Devem ser considerados dentro de certo tempo determinado pelo legislador, levando em conta as hipóteses que podem ocorrer. O Professor Roque Antonio Carraza (2009, p. 43-44) prescreve o seguinte:

Também o tributo não pode recair sobre ingressos obtidos num único momento. Desenvolvendo a ideia, os rendimentos do contribuinte devem ser considerados não isoladamente, mas dentro de um período de tempo que contenha um termo inicial e um termo final - impende referir, um dies a quo e um dies ad quem.

Analisando o Decreto n 3000/1999, vislumbra-se através da leitura do artigo 39 e seguintes que muitas situações não sofrem incidência do imposto de renda, inclusive doações e herança. 


\title{
INCIDÊNCIA DO IMPOSTO DE RENDA NAS SUCESSÕES CAUSA MORTIS DECORRENTE DE GANHO DE CAPITAL
}

O critério de periodicidade apresenta o lapso temporal, onde se configure o patrimônio inicial, o percebimento da renda ou dos proventos e derradeiramente o patrimônio final. Este é o posicionamento do Professor Roque Antonio Carraza (2009, p. 130-131):

\begin{abstract}
Ora, sendo assim, resulta incontroverso que a apuração da renda pressupõe a observância de uma periodicidade. De fato, se o conceito de renda somente pode ser obtido comparando-se os ingressos e os desembolsos efetuados, segue-se que sua apuração torna imperiosa e inafastável a consideração de um dado período de tempo. Do contrário - isto é, isolando no tempo um certo ganho -, ao invés de renda, estar-se-à tributando o patrimônio, o faturamento, o mínimo vital, e, eventualmente, até imprimindo ao tributo caráter confiscatório. Ao cabo deste raciocínio, temos por assentado que o tributo em estudo renova-se sucessivamente. Por isso mesmo, está submetido a uma periodicidade.
\end{abstract}

Nos termos do artigo $2^{\circ}$ da Lei 7713/1988, que altera a legislação do imposto de renda e dá outras providências, publicada no DOU de 23/12/1998, para as pessoas físicas o critério temporal eleito é mensal:

Art. $2^{\circ} \mathrm{O}$ Imposto sobre a Renda das pessoas físicas será devido, mensalmente, à medida em que os rendimentos e ganhos de capital forem percebidos.

A Constituição Federal é extremamente recente e, sendo ela quem emana importantes princípios, tem-se que a discussão quanto ao tema está apenas no início, apesar de sua estrondosa importância.

Considerar como base de cálculo do referido imposto simplesmente o ingresso ou possibilidade de ingresso de renda ou proventos como fato gerador é agir com imprudência, é fechar os olhos para a realidade social, retirando da economia uma parte importante da receita dos contribuintes que sequer adere ao seu patrimônio o que, sem dúvida alguma, afeta a economia como um todo.

Certamente a participação mais ativa da sociedade forçará uma melhor interpretação e análise sobre as hipóteses de incidência desse majestoso tributo, que é o imposto sobre a renda.

\section{GANHO DE CAPITAL}


Com previsão no Decreto 3000/1999, consta no artigo 117 que está sujeita a tributação pelo imposto de renda os ganhos de capital que forem obtidos na alienação de bens ou direitos de qualquer natureza.

Analisando conjuntamente com o conceito de renda, percebe-se que a falta de clareza dada pelo legislador ordinário a duas expressões importantes para análise do tema interferem na discussão sobre a legalidade do imposto.

Primeiramente, como visto no capítulo anterior, do próprio conceito e alcance jurídico dos termos “rendas' e “proventos”. Pelas disposições do CTN, o termo “proventos de qualquer natureza” previsto no inciso II do artigo 43, abarca uma infinidade de conceitos.

A doutrina tende a compreender o termo "provento" como um complemento de "renda”. Já a locução “qualquer natureza”, que estaria referindo-se a proventos e, consequentemente renda, congrega um universo inimaginável de conceitos que podem desencadear hipótese de incidência pelo referido imposto.

O mesmo ocorre em relação a importante conceituação de elementos constantes da hipótese de incidência do imposto de renda decorrente de ganho de capital. Novamente surge referência ao termo “qualquer natureza”, fazendo menção aos objetos alienados, conforme se infere no caput do artigo 117 da Decreto 3000/1999:

Art. 117. Está sujeita ao pagamento do imposto de que trata este Título a pessoa física que auferir ganhos de capital na alienação de bens ou direitos de qualquer natureza (Lei $n^{\circ} 7.713$, de 1988 , artigos $2^{\circ}$ e $3^{\circ}$, $\S 2^{\circ}$, e Lei $n^{\circ} 8.981$, de 1995, artigo 21).

Tem como hipótese de incidência geral a transferência do bem ou direito de qualquer natureza, conforme consta do parágrafo $4^{\circ}$ do artigo 117 , supra:

$\S 4^{\circ} \mathrm{Na}$ apuração do ganho de capital serão consideradas as operações que importem alienação, a qualquer título, de bens ou direitos ou cessão ou promessa de cessão de direitos à sua aquisição, tais como as realizadas por compra e venda, permuta, adjudicação, desapropriação, dação em pagamento, doação, procuração em causa própria, promessa de compra e venda, cessão de direitos ou promessa de cessão de direitos e contratos afins (Lei $\mathrm{n}^{0} 7.713$, de 1988, artigo $3^{\circ}$, § $3^{\circ}$ ).

Complementando a hipótese de incidência, referida norma legal faz referência a base de cálculo, nos seguintes termos:

Art. 138. O ganho de capital será determinado pela diferença positiva, entre o valor de alienação e o custo de aquisição, apurado nos termos dos artigos 123 


\section{INCIDÊNCIA DO IMPOSTO DE RENDA NAS SUCESSÕES CAUSA MORTIS DECORRENTE DE GANHO DE CAPITAL}

a 137 (Lei $n^{\circ} 7.713$, de 1988 , artigo $3^{\circ}$, $\S 2^{\circ}$, Lei $n^{\circ} 8.383$, de 1991, artigo $2^{\circ}$, $\S 7^{\circ}$, e Lei $n^{\circ}$ 9.249, de 1995, artigo 17).

O valor de alienação vem estampado no artigo 123 do referido Decreto e refere-se ao produto obtido com a realização de algum dos atos referidos no artigo 117 , parágrafo $4^{\circ}$.

O custo de aquisição é termo de fácil compreensão, podendo ser definido como aquilo que se pagou por determinado bem ou direito. Referido Decreto apresenta três fórmulas para constatação deste custo, dependendo da época de sua aquisição, como se verifica pelos artigos 125 a 135 e ainda, sobre bem imóvel rural, no artigo 136.

Portanto, chega-se a conclusão lógica, por força da leitura simples do artigo 138 do Decreto em questão, que haverá tributação pelo imposto de renda, a título de ganho de capital, sobre a diferença entre o valor de aquisição e alienação.

Porém, complementando ainda mais o estudo sobre a hipótese de incidência, verificase que somente será tributada a diferença positiva entre o custo de aquisição e valor de alienação, ou seja, o que ganho efetivo.

Arrisca-se a afirmar que o que se leva a tributação pelo imposto de renda seria o "lucro", "ganho efetivo” da operação de alienação, análise esta em termos amplos. Esta conclusão é importante para se chegar ao sujeito passivo da obrigação.

Em análise conjunta com o artigo 43 do CTN, o sujeito passivo deste tributo só pode ser aquele que detiver a propriedade, posse ou domínio útil da coisa e esteja autorizado a alienála, ou seja, a transferência só pode ser concretizada por aquele que detiver domínio sobre o bem ou direito.

Essa conclusão decorre de que um dos fatores para apuração da base de cálculo é o “custo de aquisição”. Portanto, o contribuinte deve de algum modo ter adquirido o bem ou direito e mais, que o tenha feito de modo que possa aliená-lo.

Como a hipótese de incidência requer transferência, o fato gerador será concretizado com a alienação. Como visto anterior, o contribuinte é aquele que pratica o ato, que realiza a ação ou omissão da norma tributária. No caso em apreço, aquele que aliena, transfere, enfim, que pratica uma das situações previstas no parágrafo quarto do artigo 117 do Decreto 3000/1999.

Há possibilidade de ser considerado como 'responsável' pelo cumprimento da obrigação uma terceira pessoa, conforme dispõe o artigo 121, inciso II do CTN. Porém, por força do artigo 128 do mesmo codex, somente será assim considerado se estiver vinculado ao fato gerador da respectiva obrigação. 
Como um dos elementos da hipótese de incidência é a diferença positiva entre aquisição e alienação, ou seja, o "ganho" experimentado, dificilmente poderá haver responsabilização de terceiro pelo cumprimento da obrigação.

Caso o "ganho" seja doado para outro sujeito, haverá a incidência do ITCMD, em razão da doação, que é o fato gerador, cuja competência é dos Estados, nos termos do artigo 155, inciso I da CF/1988.

A finalidade é tributar o ganho experimentado pelo transmitente, ou seja, a situação da valorização do bem durante o período em que esteve na propriedade, em termos gerais.

\section{GANHO DE CAPITAL NA SUCESSÃO CAUSA MORTIS}

O legislador ordinário editou norma ampliando as formas de apuração de ganho de capital, conforme Lei $n^{\circ}$ 9532/1997, que altera a legislação tributária federal e dá outras providências, publicada no DOU de 11/12/1997, inserindo a possibilidade de tributação nas sucessões causa mortis, conforme abaixo:

Art. 23. Na transferência de direito de propriedade por sucessão, nos casos de herança, legado ou por doação em adiantamento da legítima, os bens e direitos poderão ser avaliados a valor de mercado ou pelo valor constante da declaração de bens do de cujus ou do doador.

$\S 1^{\circ}$ Se a transferência for efetuada a valor de mercado, a diferença a maior entre esse e o valor pelo qual constavam da declaração de bens do de cujus ou do doador sujeitar-se-á à incidência de Imposto de Renda à alíquota de quinze por cento.

$\S 2^{\circ} \mathrm{O}$ imposto a que se referem os $\S \S 1^{\circ}$ e $5^{\circ}$ deverá ser pago: (NR)

I - pelo inventariante, até a data prevista para entrega da declaração final de espólio, nas transmissões mortis causa, observado o disposto no artigo $7^{\circ}$, § $4^{\circ}$, da Lei $\mathrm{n}^{\circ} 9.250$, de 26 de dezembro de 1995;

II - pelo doador, até o último dia útil do mês-calendário subsequente ao da doação, no caso de doação em adiantamento da legítima;

III - pelo ex-cônjuge a quem for atribuído o bem ou direito, até o último dia útil do mês subsequente à data da sentença homologatória do formal de partilha, no caso de dissolução da sociedade conjugal ou da unidade familiar. (Parágrafo com redação determinada na Lei no 9.779, de 19.1.1999, DOU 20.1.1999)

$\S 3^{\circ} \mathrm{O}$ herdeiro, o legatário ou o donatário deverá incluir os bens ou direitos, na sua declaração de bens correspondente à declaração de rendimentos do anocalendário da homologação da partilha ou do recebimento da doação, pelo valor pelo qual houver sido efetuada a transferência.

$\S 4^{\circ}$ Para efeito de apuração de ganho de capital relativo aos bens e direitos de que trata este artigo, será considerado como custo de aquisição o valor pelo qual houverem sido transferidos. 


\section{INCIDÊNCIA DO IMPOSTO DE RENDA NAS SUCESSÕES CAUSA MORTIS DECORRENTE DE GANHO DE CAPITAL}

$\S 5^{\circ}$ As disposições deste artigo aplicam-se, também, aos bens ou direitos atribuídos a cada cônjuge, na hipótese de dissolução da sociedade conjugal ou da unidade familiar.

Todavia, considerando as disposições específicas do imposto de renda decorrente de ganho de capital na alienação de bens ou direitos, de modo geral, essa tentativa não pode persistir.

Considerando-se sob a perspectiva de "ganho", o de cujus não terá sofrido nada a esse título. Não terá qualquer benefício pela valorização do bem ou direito, como ocorre na situação geral deste tributo.

O herdeiro ou legatário também não, posto que não adquiriu inicialmente e, obviamente não terá o ganho como determina as normas gerais deste tributo. Nem poderá ser considerado responsável pelo pagamento, haja vista que não é o herdeiro quem aliena. Ele apenas recebe o bem por sucessão.

Com relação a aplicação da Lei 9532/1997, sua possível aplicação somente ocorre em relação aos falecimentos ocorridos após sua vigência que, segundo consta do artigo 81, inciso II, somente ocorreu em 01 de janeiro de 1998.

Art. 81. Esta Lei entra em vigor na data de sua publicação, produzindo efeitos: I - nessa data, em relação aos artigos $9^{\circ}, 37$ a 42, 44 a 54, 64 a 68, 74 e 75;

II - a partir de $1^{\circ}$ de janeiro de 1998 , em relação aos demais dispositivos dela constantes.

Considerando que há transmissão por sucessão no momento do falecimento, conforme se dessume dos artigos 1784 e 1788 do CC, somente os óbitos ocorridos a partir de 01 de janeiro de 1998 é que poderão, em tese, sofrer as consequências da lei, sob pena de ofensa ao art. 150, inciso III, alíneas a e b, da CF/1988.

O entendimento jurisprudencial segue no mesmo sentido:

MANDADO DE SEGURANÇA. TRIBUTÁRIO. IMPOSTO DE RENDA. GANHO DE CAPITAL. ART. 23 DA LEI N ${ }^{\circ}$ 9.532/97. INSTRUÇÃO NORMATIVA SRF N ${ }^{\circ}$ 53/98. ABERTURA DE SUCESSÃO ANTES DE SUA VIGÊNCIA. NÂO ALCANCE. 1. Aberta a sucessão hereditária em momento anterior à vigência do art. 23, da Lei n ${ }^{\circ}$ 9.532/97, que determina a incidência de Imposto de Renda sobre ganho de capital, sobre a diferença do valor dos bens e direitos transmitidos por herança e o valor constante na última declaração de imposto de renda do de cujus, permanecem as disposições da Lei $n^{\circ} 7.713 / 88$, art. 6º inciso XVI e art. 22, inciso III, que, respectivamente, isentam de Imposto de Renda o valor dos bens e direitos adquiridos por herança ou doação e não tributam o ganho de capital deles decorrentes. 2 . Inteligência dos art. 104, 105 e 116, do Código Tributário Nacional. 3.0 art. $8^{\circ}$, § $1^{\circ}$, da Instrução Normativa no 53/98, no ponto em que determina sua aplicação mesmo nos casos em que o espólio tenha se iniciado antes de 01-01-98, desborda das lindes 
legais. 4. Precedentes do Colendo STJ, desta E. Corte e das Cortes da $2^{\mathrm{a}}$ e $4^{\mathrm{a}}$ Região. 5. Apelo da União e remessa oficial a que se nega provimento. (TRF $3^{\mathrm{a}}$ R.; AMS 244662; Proc. 1999.61.00.056622-3; Rel. Juiz Fed. Conv. Roberto Jeuken; DEJF 12/11/2008.)

Questão a ser debatida é sua aplicação em relação às aberturas de sucessão ocorridas após 01 de janeiro de 1998. Como acima explanado, considerando que o de cujus deixou de obter "ganho de capital” com a transferência em razão do falecimento, não ocorre o fato gerador.

Como a hipótese de incidência pressupõe a existência desse "ganho de capital”, na sucessão causa mortis estaria afastada a incidência dessa norma. Essa exegese é extraída da interpretação dada ao artigo 43 do CTN, que aponta como fator de incidência do imposto a renda ou provento de qualquer natureza.

O espólio e muito menos o de cujus não auferem renda ou proventos com a transferência dos bens por sucessão causa mortis, portanto não praticam o fato gerador, não exercitando a hipótese de incidência.

Ainda, o herdeiro não pode ser considerado como ‘terceiro responsável’ uma vez que não guarda relação com um dos elementos constantes da hipótese de incidência, que exige “ganho” decorrente da diferença entre o valor de aquisição e o valor de transferência.

Ele não está transferindo nada porque nunca teve o bem ou direito antes. Para se constatar "ganho", como conceito de renda, deve, ao menos ter adquirido o bem ou direito em período anterior para posterior transferência. Em nenhuma dessas hipóteses se insere o herdeiro, legatário, meeiro.

O de cujus também não auferirá qualquer renda ou provento com a transferência causa mortis. O espólio da mesma forma, tanto é que após a homologação da partilha ele se encerra, não tendo personalidade jurídica.

Ressalte-se que a transferência de bens por sucessão já é tributada pelo ITCMD, cuja competência é exercida pelos Estados, nos termos do artigo 155, inciso I da CF/1988. O entendimento da jurisprudência atenta para esse fato:

TRIBUTÁRIO. MANDADO DE SEGURANÇA. IMPOSTO DE RENDA PESSOA FÍSICA. SUCESSÃO. VARIAÇÃO PATRIMONIAL. GANHO DE CAPITAL. ART. 24 DA LEI N. 9.532/97. ART. 35, DO CTN. INCONSTITUCIONALIDADE DA EXAÇÃO. 1. Segundo entendimento da corte especial deste tribunal, o irpf nos termos do art. 24, da Lei n. 9.532/97 abrange o mesmo fato jurídico do imposto de transmissão causa mortis e doação, uma vez que se calcula este último, tomando-se por base o valor atualizado dos bens. Valor de mercado obtido mediante avaliação. 2. A jurisprudência vem prevalecendo no sentido da inconstitucionalidade da exação (TRF $1^{\text {a }}$ região. Iinams 1998.38.00.027179-5/MG. Corte especial, DJ de 3/8/2007) e, 


\section{INCIDÊNCIA DO IMPOSTO DE RENDA NAS SUCESSÕES CAUSA MORTIS DECORRENTE DE GANHO DE CAPITAL}

também, o Excelso Supremo Tribunal Federal (re 32979, re. Min. Ribeiro da costa, $2^{\mathrm{a}}$ turma, julgado em 15/1/1957, ementa vol. 00298-02 pp. 00882). 3. Apelação dos impetrantes provida. Segurança concedida. TRF $1^{\mathrm{a}}$ R.; AC 1998.38.00.046234-3; MG; Oitava Turma; Rel. Juiz Fed. Conv. Cleberson José Rocha; Julg. 04/12/2009; DJF1 29/01/2010)

Em análise proferida pelo Tribunal Regional Federal da $1^{\text {a }}$ Região, nos autos de apelação cível nº 1999.38.00.039334/MG, consignou-se o seguinte entendimento:

"O fato gerador da obrigação discutida está assim definido pelo artigo 23 da Lei n. 9.532/97:

'Na transferência de direito de propriedade por sucessão, nos casos de herança, legado ou doação em adiantamento da legítima, os bens e direitos poderão ser avaliados a valor de mercado ou pelo valor constante da declaração de bens do de cujus ou do doador.

$\S 1^{\circ}$ Se a transferência for efetuada a valor de mercado, a diferença a maior entre esse e o valor pelo qual constavam da declaração de bens do de cujus ou do doador sujeitar-se-á à incidência de imposto de renda à alíquota de quinze por cento'

Vê-se, portanto, que o mencionado diploma pretendeu instituir a cobrança de imposto de renda sobre o acréscimo patrimonial obtido por herdeiros ou legatários, decorrente da diferença verificada entre o valor do bem lançado na declaração de bens do ‘de cujus' ou do doador e seu valor de mercado.

Ocorre que a abertura do testamento ou efetivação da doação não tem o condão de produzir outro acréscimo patrimonial fora o decorrente da transmissão em si.

Na verdade, se tal bem sofreu alguma valorização econômica esta ocorreu quando ele ainda encontrava-se no patrimônio do "de cujus" ou doador, não pelo simples fato de ter sido transferido para o patrimônio do herdeiro ou donatário.

Deste modo, o momento para que a União corretamente tributasse com imposto de renda os ganhos de capitais produzidos pelos bens em questão, era quando estes se encontravam no patrimônio do "de cujus" ou doador, se não o fez, por razões que na vêm ao caso, não poderá realizá-lo quando tais bens já foram transferidos para o patrimônio do herdeiro ou donatário, sob pena de estar instituindo imposto de renda sobre fato gerador de ente federativo diverso, o que lhe é defeso nos termos dos artigos $7^{\circ}$ do CTN e 154 da CF/88.

É que, conforme demonstrado, o imposto de renda está, na verdade, incidindo sobre a própria transmissão dos bens doados ou herdados, que nos termos do artigo 155, inciso I da CF/88 constitui fato gerador do ITCD.

Desta forma, diante da inexistência de um dos elementos constantes da hipótese de incidência do imposto de renda decorrente de ganho de capital nas sucessões causa mortis, qual seja, o próprio ganho de capital entendido como renda ou faturamento, nos exatos termos do artigo 43 do CTN, a exação pretendida pelo advento da lei 9532/1997 não merece guarida. 
Tampouco pode ser atribuída a responsabilidade pelo cumprimento da obrigação para terceiro, em especial o herdeiro, legatário ou meeiro, em razão de que estes não guardam qualquer relação com o fato gerador, posto que não transferem o bem ou direito, além de jamais tê-lo possuído em período anterior, portanto, não poderiam aliená-los e, consequentemente auferir renda ou proventos decorrentes de ganho de capital.

\section{CONSIDERAÇÕES FINAIS}

Pela análise de conceitos dos termos jurídicos da seara tributária, o imposto de renda sobre possível ganho de capital nas sucessões causa mortis não se justifica. Primeiramente quanto ao percebimento de renda ou proventos de qualquer natureza, fica claro que o de cujus ou o espólio não praticam a hipótese de incidência. Não experimentam lucro ou ganho de capital, propriamente dito.

O herdeiro, legatário ou meeiro também não obtém renda tributável, nos termos do CTN, passível de incidência do imposto de renda. A herança é isenta, nos termos Decreto ${ }^{\circ}$ 3000/1999, incidindo tão somente o ITCMD.

Tampouco podem ser considerados sujeito passivo da obrigação tributária, pois não realizam a conduta prescrita pela hipótese de incidência, logo, não praticam o fato gerador. Não fazem a transferência, portanto, não experimental ganho algum.

A legislação até permite que eventualmente terceiro possa ser responsabilizado por obrigação tributária, porém, requer no mínimo uma vinculação com o fato gerador. No caso das sucessões causa mortis apenas recebem a herança em razão da condição de herdeiro. Nada mais que isso.

A hipótese de incidência é a possibilidade de que, determinado agir, desencadeie alguma espécie de obrigação tributária. É uma situação abstrata que, ao ser exercitada pelo contribuinte, gera o dever de cumprir com a obrigação determinada pelo mesmo tipo legal.

No caso de recebimento de herança, a hipótese de incidência já considera o fato gerador isento do imposto de renda, como visto anteriormente. Ora, independe se o bem foi adquirido pelo finado por determinado valor e transmitido por outro. A regra geral é de isenção, não havendo que se falar em obrigação de recolhimento em situação particularizada, decorrente do mesmo fato gerador, qual seja, o recebimento de herança. 


\section{INCIDÊNCIA DO IMPOSTO DE RENDA NAS SUCESSÕES CAUSA MORTIS DECORRENTE DE GANHO DE CAPITAL}

O conceito de renda, como visto alhures, precisa ser contextualizado. O recebimento de herança não é um fator corriqueiro na vida dos contribuintes, não podendo ser considerado como ensejador do imposto de renda. A própria legislação específica o considera como isento.

Considerando que não se tributa herança pelo imposto de renda, não seria lógico tributar suposto ganho de capital em razão de que o finado adquiriu bem por um valor e transmitiu por outro, superior.

Por expressa disposição legal, qualquer recebimento de herança é isento do imposto de renda, independentemente do valor pelo qual o bem tenha sido originariamente adquirido pelo transmitente da herança.

O que o fisco pretende fazer é desvirtuar conceitos jurídicos, alargando a hipótese de incidência para dar guarida à tentativa de cobrança de tributo evidentemente ilegal. Tenta instituir cobrança de imposto de renda nas sucessões causa mortis sob o pretexto do lucro imobiliário.

Como externado neste trabalho, o Estado não tem o poder de criar tributos, a seu bel prazer. O que está constitucionalmente autorizado é instituir tributo, dentro de sua competência, obedecendo ao regramento já existente, especialmente o alcance dos termos jurídicos.

Por tais razões, a conclusão é de que a exação pelo imposto de renda decorrente de ganho de capital nas sucessões causa mortis é ilegítima, ainda mais quando se tratar de falecimento ocorrido em período anterior à vigência da lei 9532/1997.

A tentativa da União Federal em instituir o tributo, ora analisado, tem por finalidade suprir a lacuna deixada na possibilidade de reavaliação dos bens. Como se sabe, atualmente a legislação federal não permite que os bens tenham seus valores atualizados na declaração do imposto de renda, salvo em decorrência de reforma, ampliação, devidamente comprovada.

Como a morte é inevitável, certamente muitos contribuintes deixam para fazer essa reavaliação no inventário, transmitindo ao herdeiro por valor superior ao constante na declaração do imposto de renda do finado.

Entretanto, tentar igualar o fato gerador previsto para os demais casos de ganho de capital, onde há efetivamente ganho por parte do transmitente, nas sucessões causa mortis não é de boa técnica jurídica.

São situações diferentes, onde o fator principal, qual seja, o ganho por parte do transmitente, absolutamente inexiste. Ainda, o herdeiro não tem qualquer relação com a hipótese de incidência. 
O único imposto devido pelo herdeiro é o ITCMD, que incide sobre a transmissão da herança e a base de cálculo para esse tributo é o valor venal dos bens.

É fácil perceber uma contradição do Fisco. Exige-se valor atualizado para recolhimento do ITCMD, mas se esse valor for lançado na declaração do imposto de renda do herdeiro, será tributo por ganho de capital.

Definitivamente, não é de boa técnica a saída encontrada pelo Estado para tributar pelo imposto de renda as transmissões causa mortis.

\section{REFERÊNCIAS:}

AMARO, Luciano. Direito Tributário Brasileiro. 17. ed. São Paulo: Saraiva, 2011. BECHO, Renato Lopes. Filosofia do Direito Tributário. São Paulo: Saraiva, 2009.

BONAVIDES, Paulo. Ciência Política. 19. ed. São Paulo: Malheiros, 2012.

CARRAZA, Roque Antonio. Curso de Direito Constitucional Tributário. 28 ed., rev., ampl. e atual. São Paulo: Malheiros, 2012.

Imposto sobre a Renda: perfil constitucional e temas específicos. 3. ed. São

Paulo: Malheiros, 2009.

De Plácido e Silva, Vocabulário Jurídico. 28 ed. Rio de Janeiro: Forense, 2009.

FREITAS, Vladimir Passos de. Código Tributário Nacional Comentado. 4. ed. rev., at. e ampl. São Paulo: Revista dos Tribunais, 2007.

LEMKE, Gisele. Imposto de Renda: Os Conceitos de Renda e de Disponibilidade

Econômica e Jurídica. São Paulo: Dialética, 1998.

MACHADO, Hugo de Brito. Curso de Direito Constitucional Tributário. São Paulo: Malheiros, 2012.

MEIRELLES, Hely Lopes. Direito Administrativo Brasileiro. 38. São Paulo: Malheiros, 2012.

MINATEL, José Antonio. Conteúdo do Conceito de Receita e Regime Jurídico para sua Tributação. São Paulo: MP Editora, 2005.

MONTOURO, André Franco. Introdução à Ciência do Direito. 29. ed. rev. e at. São Paulo: Revista dos Tribunais, 2011.

MORAES, Alexandre de. Constituição do Brasil Interpretada e Legislação

Constitucional. 6. ed. São Paulo: Atlas, 2006. 


\section{INCIDÊNCIA DO IMPOSTO DE RENDA NAS SUCESSÕES CAUSA MORTIS DECORRENTE DE GANHO DE CAPITAL}

MESSA, Ana Flávia. Direito Tributário: direito material. São Paulo: Ridel, 2010.

NADER, Paulo. Introdução ao Estudo do Direito. 22. ed. rev. e at. São Paulo: Forense, 2002.

PAULSEN, Leandro; MELO, José Eduardo Soares. Impostos Federais, Estaduais e Municipais. 7. Ed. Porto Alegre: Livraria do Advogado, 2012

PROCHALSKI, Prochalski. ISS Regra Matriz de Incidência e Conflitos de Competência. Curitiba: Juruá, 2009.

QUEIROZ, Mary Elbe. Imposto sobre a renda e proventos de qualquer natureza. Barueri: Manole, 2004.

SABBAG, Eduardo. Manual de Direito Tributário. 4. ed. São Paulo: Saraiva, 2012, p. 59

SCHOUERI, Luis Eduardo. Direito Tributário. 2. ed. São Paulo: Saraiva, 2012.

SILVA, José Afonso da. Curso de Direito Constitucional Positivo. 35 ed., rev. e atual. São Paulo: Malheiros, 2012. 